\title{
EVALUATION OF THE EFFECT OF PLATELET RICH FIBRIN ON BONE HEALING AFTER SURGICAL REMOVAL OF IMPACTED MANDIBULAR THIRD MOLAR
}

\author{
Wageeh $\mathrm{E}^{1}$, Osman $\mathrm{S}^{2}$, Fahmy $\mathrm{M}^{2}$
}

\begin{abstract}
Introduction: Following the extraction of impacted mandibular third molars, there is a risk for developing new, or having persistent osseous periodontal defects on the distal aspects of the adjacent second molars.

Objectives: To evaluate the effect of platelet rich fibrin (PRF) on bone healing distal to the second molar following removal of impacted mandibular third molar.

Materials and methods: This was a parallel, controlled and randomized clinical trial. Twenty patients aged between 20-30 years, who have mesioangular position B impacted mandibular third molar indicated for surgical removal were selected for this study. Ten patients were taken for the study group, where PRF was applied in the extraction socket of the mandibular third molar and 10 patients for the control group, where the extraction sockets were sutured without receiving PRF. The patients were evaluated clinically for pain, edema and trismus on the second, fourth and seventh day post-operatively and radiographically on the first, second and third month post-operatively. Standardized periapical x-ray films were taken for each patient preoperatively and on the first, second and third postoperative months. Image-J Processing Program was used for the assessment of new bone formation at the distal surface of the second molar.
\end{abstract}

Results: There was less pain and trismus in the study group than in the control group but the difference among them was not statistically significant $(p>0.05)$. Edema was significantly lower in the study group than in the control group in the second and fourth postoperative days. There was significantly more bone density and higher bone level in the study group than in the control group on the second and third postoperative months $(\mathrm{p}<0.05)$.

Conclusion: It is clear that PRF is biocompatible and can improve both soft tissue healing and bone regeneration after surgical removal of impacted mandibular third molar.

Key Words: Platelet rich fibrin, Impacted third molar, Extraction socket, Bone density.

1. B.D.S. Faculty of Dentistry, Alexandria University, Alexandria, Egypt

2. Professor of Oral \& Maxillofacial Surgery, Faculty of Dentistry, Alexandria University, Alexandria, Egypt

\section{INTRODUCTION}

Mandibular third molars are the most frequently impacted teeth $(1,2)$. Surgical removal of third molars is the most common surgical procedure performed in the specialty of oral and maxillofacial surgery (3). Their surgical removal is often accompanied by pain, swelling, trismus and general oral dysfunction during the healing phase (4).

Following the extraction of impacted mandibular third molars, there is a risk for developing new, or having persistent osseous periodontal defects on the distal aspects of the adjacent second molars (5).

Maxillofacial reconstructions, oral implants, regenerative procedures etc. are highly dependent on successful regeneration and healing, and one of the great challenges faced in clinical researches is the development of bioactive surgical additives regulating inflammation and increasing healing. Bone regenerative techniques including graft materials, protein and barrier membrane are often used to improve the bone quality. Healing in tissues is mediated by variety of signaling proteins. Understanding of this process at microcellular level is still not complete, but it is proven fact that platelets play an important role in wound healing (6).

Platelets contain a number of different growth factors which are released into the tissues after injury. These include transforming growth factor beta (TGF- $\beta$ ), platelet derived growth factor (PDGF), insulin-like growth factors (IGFs), vascular endothelial growth factor (VEGF) and fibroblast growth factors (FGFs) which act as differential factors on regenerating periodontal tissues $(7,8)$.

It has been shown in several studies that bone regenerative procedures may be enhanced by the addition of specific growth factors (9). Platelet rich plasma (PRP) was used as a method of introducing concentrated growth factors to the surgical site, thereby enriching the natural blood clot in order to hasten wound healing and stimulate bone regeneration (10).

The PRP preparation protocol requires collection of blood with anticoagulant, centrifugation in two steps and induced polymerization of the platelet concentrate using calcium chloride and bovine thrombin (11).

It has been discovered that the use of bovine thrombin may result in the stimulation of the immune system when challenged with a foreign protein (12).

The PRP protocols were both expensive and time consuming and their development in private practice remains quite limited (13).

Platelet rich fibrin (PRF) was first developed in France by Choukroun et al (14) in 2001. This second generation platelet concentrate eliminates the risk associated with the use of bovine thrombin. It represents a new step in the platelet gel therapeutic concept with simplified processing without artificial biochemical modification (15).

Unlike other platelet concentrates this technique requires neither anticoagulants nor bovine thrombin (nor any 
other gelifying agent), making it no more than centrifuged natural blood without additives (16).

Advantages of PRF over PRP include no biochemical handling of blood, simplified and cost-effective process, the use of bovine thrombin and anticoagulants is not required, favorable healing due to slow polymerization, and more efficient cell migration and proliferation. Also PRF has supportive effect on immune system, and it helps in hemostasis (17).

The biochemical analysis of the PRF composition indicates that this biomaterial consists of an intimate assembly of cytokines, glycanic chains, structural glycoproteins enmeshed within a slowly polymerized fibrin network. These biochemical components have well known synergetic effects on healing processes (18).

PRF is believed to release six growth factors; platelet derived growth factor (PDGF), vascular endothelial growth factor (VEGF), transforming growth factor (TGF), insulinlike growth factors (IGFs), epithelial growth factor (EGF) and recombinant human basic fibroblast growth factor (bFGF) (19).

The intrinsic incorporation of cytokines within the fibrin mesh allows for their progressive release over time (711) days, as the network of fibrin disintegrates (20).

The easily applied PRF membrane acts much like a fibrin bandages, serving as a matrix to accelerate the healing of wound edges $(6,21)$. It also provides a significant postoperative protection of the surgical site and seems to accelerate the integration and remodeling of the grafted biomaterial $(18,22)$.

PRF is not only a platelet concentrate but also immune node able to stimulate defense mechanisms. It is likely that the significant inflammatory regulation noted on surgical sites treated with PRF is the outcome of retro control effects from cytokines trapped in the fibrin network and released during the remodeling of this initial matrix (23).

Because of the absence of an anticoagulant, blood begins to coagulate as soon as it comes in contact with the glass surface. Therefore, for successful preparation of PRF, speedy blood collection and immediate centrifugation, before the clotting cascade is initiated, is absolutely essential (15).

The aim of this study was to evaluate the effect of PRF on bone healing distal to the second molar following removal of the impacted mandibular third molar.

\section{MATERIALS AND METHODS \\ Study design}

This study was a parallel, controlled and randomized clinical trial.

\section{Selection of patients}

This study was conducted on 20 patients who were selected, and operated in the Oral \& Maxillofacial Surgery department, Faculty of Dentistry, Alexandria University, Egypt. Each patient had been informed about the nature of this study and gave an informed consent.

The patients with mesioangular position B impacted mandibular third molar indicated for surgical extraction were included in this study. These 20 patients were divided into two equal groups.

1- Control group: Consists of 10 patients, where the sockets of the extracted mandibular third molars were left without receiving PRF.

2- Study group: Consists of 10 patients, where PRF was applied in the extraction socket of the mandibular third molar.

\section{Inclusion Criteria of selection}

- Patient's age ranged from 20 to 30 years.

- Patients with mesioangular position B impacted mandibular third molar indicated for surgical removal.

- The adjacent second molars were fully erupted and healthy.

\section{Exclusion criteria of selection}

- Medically compromised patients.

- Patients under anticoagulant therapy.

- Patients with acute pericoronitis.

I. Materials

Platelet-rich fibrin (PRF) was prepared by centrifugation of $10 \mathrm{ml}$ of whole blood of the patient in a table centrifuge (figure 1a) (model 800, manufactured by China Yangzhou Guotoi Co., LTD) at 3000 revolution per minute (rpm) for 10 minutes (24). The resultant product consisted of the following three layers:

- Top most layer consisting of acellular platelet poor plasma (PPP)

- PRF clot in the middle.

- RBCs at the bottom. (Figure 1b)

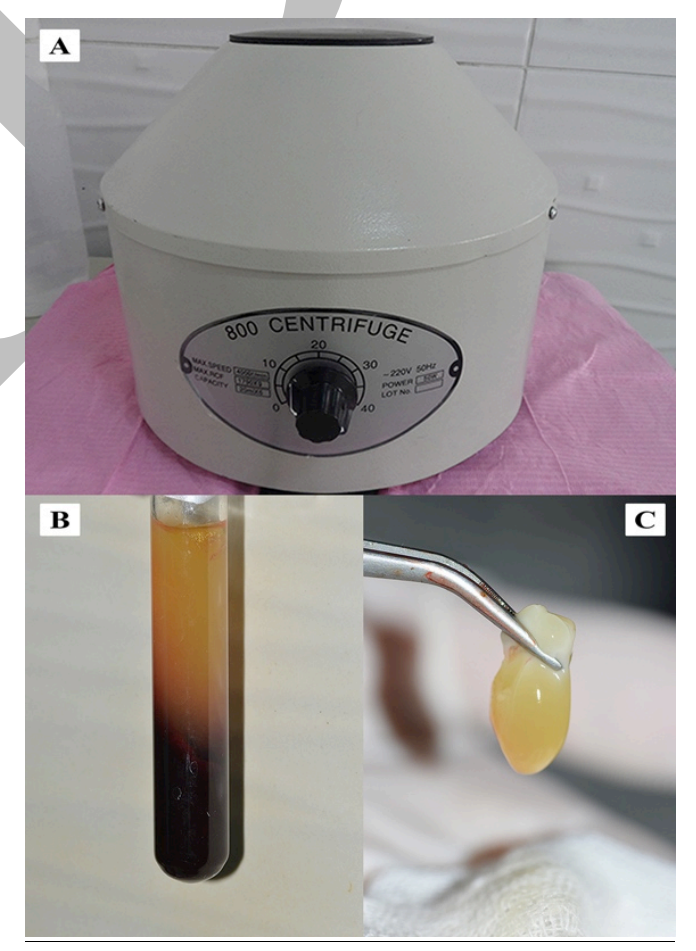

Fig. 1: a. Centrifuge machine.

b. Blood sample after centrifugation.

c. PRF separated from the blood. 
A fibrin clot was then obtained in the middle of the tube, just between the red corpuscles at the bottom and acellular plasma at the top. PRF was then separated from PPP and RBC layer, ready for application in the extraction socket. (Figure 1c)

\section{II- Methods \\ 1- Pre-operative phase \\ A. Clinically}

All the patients were subjected to intra oral examination to determine the stage of eruption of the impacted third molar.

B. Radiographically

Standardized periapical $\mathrm{x}$-ray films and panoramic views (0.P.G) were taken for all patients to evaluate the classification of the impacted mandibular third molar and the amount of the bone related to it.

\section{2- Operative phase}

Surgical procedure

- All the patients were given local anesthetic (Mepecaine-L carpalia product of Alexandria Company for Pharmaceutics and Chemical Industties, Alexandria. (Mepecaine HCL 2\% with Levonordin 1: 20000).

- Incision and reflection of extended buccal mucoperiosteal flap with a periosteal elevator (figure $2 \mathrm{a}$ ).

- Bone removal was done by guttering technique and the tooth is then sectioned and elevated from its socket (figure $2 b$ ).

- Trimming and filing of irregular bony edges with a bone file.

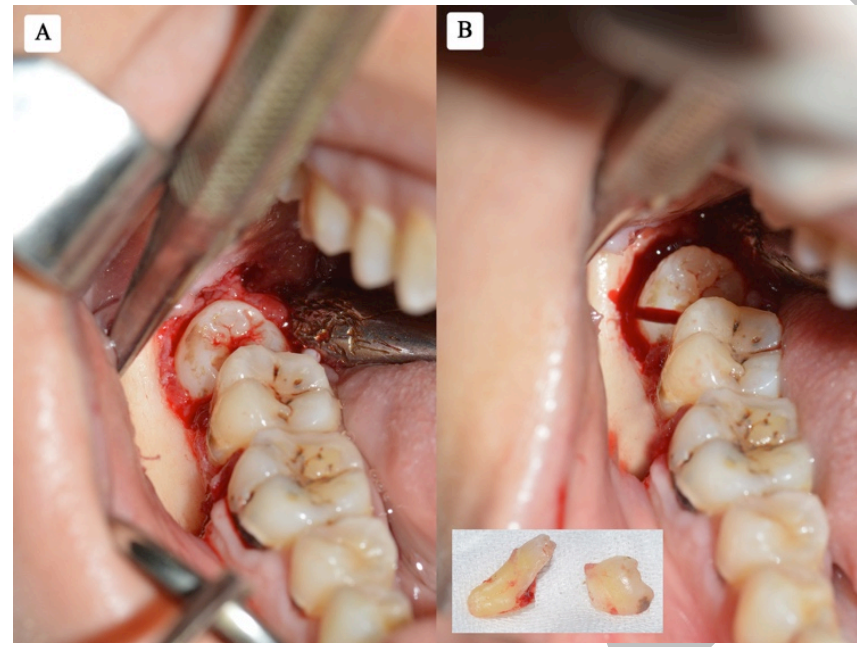

Fig. 2: a. Reflection of mucoperiosteal flap and exposure of the tooth. b. Bone guttering and tooth sectioning and removal.

\section{Control group}

- The sockets of the extracted mandibular third molars remained empty (Figure 3a).

- The flap was repositioned and sutured with 3-0 black silk sutures.

\section{Study group}

- PRF was applied in the extraction socket (figure 3b).

- The flap was repositioned and sutured with 3-0 black silk sutures (figure 4).

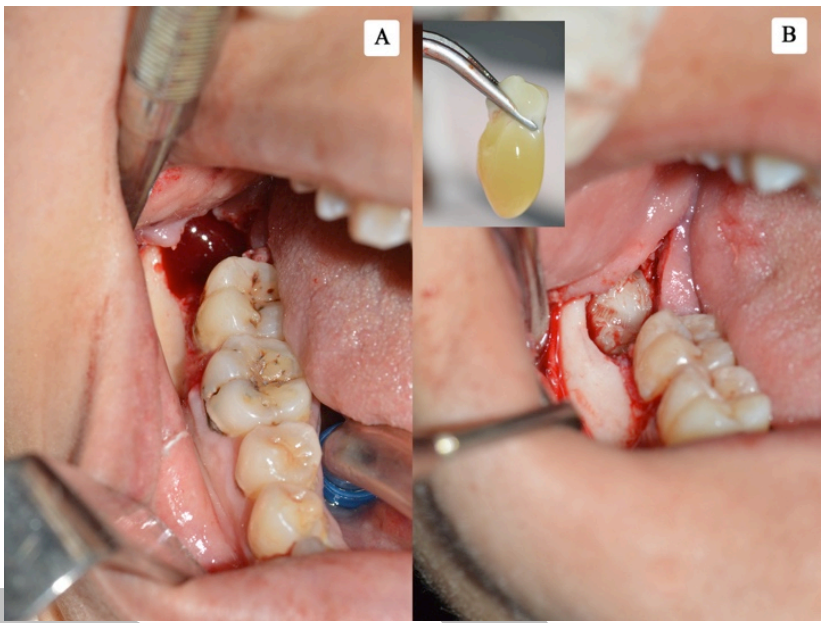

Fig. 3: a. Empty socket after tooth removal (control case) b. PRF separation and placement inside the extraction socket (study case)

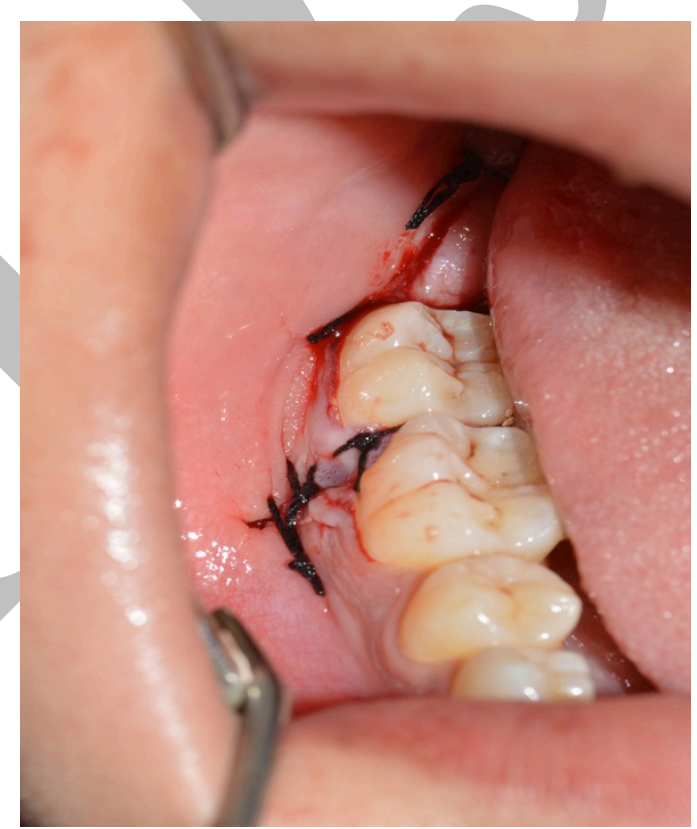

Fig.4: Suturing of the flap.

\section{3- Postoperative phase}

- Post-operative antibiotic: Amoxicillin \& Clavulanate Potassium 1gm (Augmentin: manufactured by Medical Union Pharmaceuticals.) (Twice daily for four days), and analgesic: Diclofenac Potassium 50mg (Cataflam: manufactured by Novartis Pharma Company.) (Every 8 hours for three days) were prescribed.

- The stitches were removed after 7 days.

4- Follow up and criteria of evaluation

The post-operative evaluation was done clinically and radiographically for both groups as follows: 
(A) Immediate post-operative evaluation

\section{1) Postoperative healing}

The wound was evaluated clinically on second, fourth and seventh day post-operatively regarding the presence or absence of wound dehiscence, bleeding or inflammation.

\section{2) Postoperative pain}

Pain was evaluated though VAS (visual analogue scale) on the second, fourth and seventh day postoperatively, taking pain scores from 0 to 5 (25). Patients were asked about the pain severity according to (VAS) as follows:
0 No pain
1 Slight pain
2 Mild pain
3 Severe pain
4 Very severe pain
5 Extremely severe pain

Standardized periapical x-ray films were taken for each patient at first, second and third month post-operatively (figure 5and 6) by XCP device (The XCP devices is produced by Rinn Crop, Elgin, Illinois, USA) with a rubber base bite for each patient to standardize the x-rays.

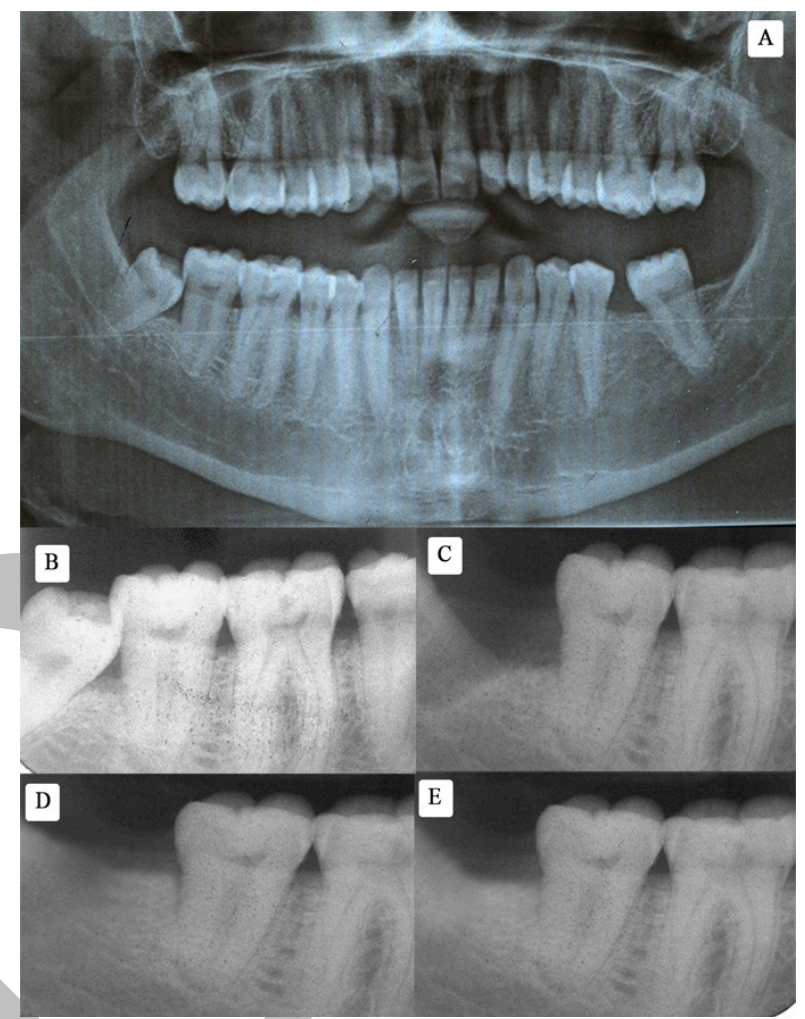

Fig. 5: a. Preoperative panoramic radiograph (control case). b. Preoperative periapical film.

c. First month postoperatively.

d. Second month postoperatively.

e. Third month postoperatively.$$
-
$$

- The standardized periapical x-ray films were scanned by using a transparent scanner and saved on the computer in files according to the patient's name. Then Image-J Processing Program (Wayne resband (wayne (a)codon.noh.gov). National Institute of Health, USA.) was used for the assessment of the amount of new bone formation and bone density at the distal surface of the second molar.

\section{A-Evaluation of the bone density}

1- The bone density was recorded on the first, second and third month post-operatively.

2- A circle was drawn at the distal surface of mandibular second molar (inside the socket) on the scanned film.

3- The area was measured by choosing ROI manager from tools, from analyze.

4- The same circle was drawn for each X-ray film for all patients, the bone density was measured and the results were subjected to statistical analysis.

\section{2- Radiographic evaluation}




\section{B-Evaluation of the bone height (level)}

The alveolar bone height for all scanned films was digitally measured from the cement-enamel junction (CEJ) to the alveolar bone crest $(\mathrm{ABC})$ on the distal aspect of the mandibular second molars.

The bone height was recorded on the first, second and third post-operative months.

\section{Statistical analysis of the data}

Data were fed to the computer and analyzed using IBM SPSS software package version 20.0 (27). Quantitative data were described using range (minimum and maximum), mean, standard deviation and median. The distributions of quantitative variables were tested for normality using Kolmogorov-Smirnov test, Shapiro-Wilk test and D'Agstino test. If it reveals normal data distribution, parametric tests was applied. If the data were abnormally distributed, nonparametric tests were used. For normally distributed data, comparison between two independent population were done using independent t-test, comparison between different periods using ANOVA with repeated measures and Post Hoc test (LSD). For abnormally distributed data, comparison between two independent population were done using Mann Whitney test. To compare between the different periods Friedman test was applied and Wilcoxon signed ranks test. Significance of the obtained results was judged at the $5 \%$ level.

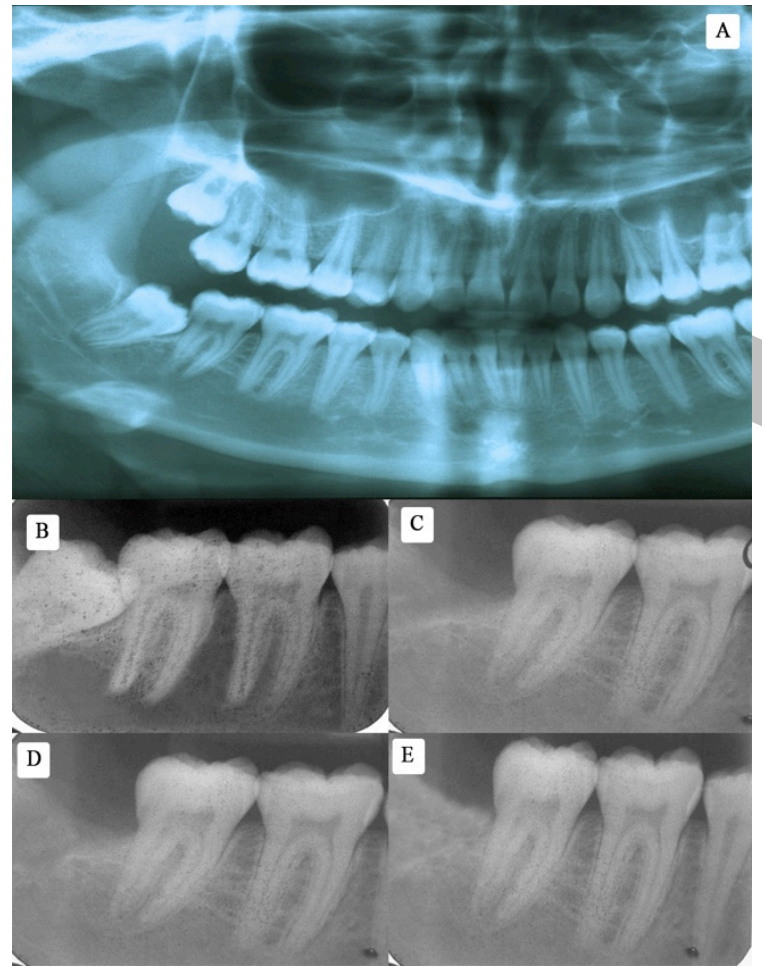

Fig. 6: a. Preoperative panoramic radiograph (study case).

b. Preoperative periapical film.

c. First month postoperatively.

d. Second month postoperatively.

e. Third month postoperatively.

\section{RESULTS}

In this study, twenty patients having mesioangular position $\mathrm{B}$ impacted mandibular third molar were divided equally into 2 groups:

- Group 1 (control group) consisting of 10 patients and included 5 males and 5 females.

- Group 2 (study group) consisting of 10 patients and included 3 males and 7 females.

\section{A) Clinical follow up}

1) Postoperative pain

There was less pain in the study group than in the control group: the relation was not statistically significant on the second, fourth and seventh day $(\mathrm{p}=0.115,0.058$ and 0.070 respectively).

\section{1) Postoperative edema}

There was less edema in the study group than in the control group: the relation was statistically significant on the second and fourth post-operative days $(\mathrm{p}=0.030,0.008$ respectively) and not significant on the seventh day $(\mathrm{p}=0.298)$.

\section{3) Postoperative trismus (mouth opening)}

There was less trismus in the study group than the control group. The relation between the two groups was not statistically significant on the second, fourth and seventh post-operative days ( $\mathrm{p}=0.415,0.104$ and 0.110 respectively).

\section{B) Radiographic follow up 1) Bone density}

Table (1) shows the comparison among the control and study groups as regards bone density.

Table 1: Comparison among the control and study groups as regards bone density.

\begin{tabular}{|c|c|c|c|c|c|}
\hline & \multicolumn{3}{|c|}{ Post-operative } & \multirow{2}{*}{$\mathbf{F}$} & \multirow{2}{*}{$\mathbf{P}$} \\
\hline & $1^{\text {st }}$ month & $2^{\text {nd }}$ month & $3^{\text {rd }}$ month & & \\
\hline \multicolumn{6}{|l|}{ Control cases $(n=10)$} \\
\hline Min. - Max. & $51.0-71.08$ & $52.90-74.97$ & $58.0-84.49$ & & \\
\hline Mean \pm SD & $57.99 \pm 6.09$ & $62.29 \pm 6.95$ & $65.16 \pm 7.70$ & $5.139^{*}$ & $0.019^{*}$ \\
\hline Median & 57.0 & 61.71 & 62.92 & & \\
\hline Sig. bet. periods & \multicolumn{3}{|c|}{$\mathrm{p}_{1}=0.014^{*}, \mathrm{p}_{2}=0.016^{*}, \mathrm{p}_{3}=0.384$} & & \\
\hline \multicolumn{6}{|l|}{ Study cases $(n=10)$} \\
\hline Min. - Max. & $47.97-69.91$ & $58.20-76.45$ & $61.90-83.30$ & & \\
\hline Mean \pm SD. & $58.32 \pm 7.04$ & $68.23 \pm 5.13$ & $73.04 \pm 6.47$ & $17.887^{\circ}$ & $<0.001^{*}$ \\
\hline Median & 57.79 & 68.0 & 74.41 & & \\
\hline Sig. bet. periods & \multicolumn{3}{|c|}{$\mathrm{p}_{1}=0.001^{*}, \mathrm{p}_{2}<0.001^{*}, \mathrm{p}_{3}=0.058$} & & \\
\hline $\mathbf{T}$ & 0.117 & 2.364 & $2.719^{*}$ & & \\
\hline $\mathbf{P}$ & 0.908 & $0.028^{*}$ & $0.013^{*}$ & & \\
\hline \multicolumn{6}{|c|}{$\begin{array}{l}\text { F: F test for ANOVA with repeated measures, sig. bet. periods was dor } \\
\text { (LSD) } \\
\text { t: Student t-test } \\
p_{1}: p \text { value for comparison between } 1^{\text {st }} \text { with } 2^{\text {nd }} \text { month post-operatively } \\
p_{2}: p \text { value for comparison between } 1^{\text {st }} \text { with } 3^{\text {rd }} \text { month post-operatively } \\
p_{3}: p \text { value for comparison between } 2^{\text {nd }} \text { with } 3^{\text {rd }} \text { month post-operatively } \\
\text { *: Statistically significant at } p \leq 0.05\end{array}$} \\
\hline
\end{tabular}

Starting from the first to the third month post operatively, there was slightly denser bone in the study group than in the control group. The difference among the 
two groups was not statistically significant on the first postoperative month $(\mathrm{p}=0.908)$, but it was statistically significant on the second and third post-operative months ( $\mathrm{p}=0.028,0.013$ respectively).

\section{2) Bone height}

Table (2) shows the comparison among the control and study groups as regards the bone height which has been measured radio-graphically from the cement-enamel junction (CEJ) to the alveolar bone crest $(\mathrm{ABC})$ on the distal aspect of the mandibular second molars.

Table 2: Comparison among the control and study groups as regards the bone height.

\begin{tabular}{|c|c|c|c|c|c|c|}
\hline & \multirow{2}{*}{ Pre-operative } & \multicolumn{3}{|c|}{ Post-operative } & \multirow{2}{*}{$\mathbf{F}$} & \multirow[b]{2}{*}{ p } \\
\hline & & $1^{\text {st }}$ month & $2^{\text {nd }}$ month & $3^{\text {rd }}$ month & & \\
\hline $\begin{array}{c}\text { Control cases } \\
(n=10)\end{array}$ & & & & & & \\
\hline Min. - Max. & $2.92-5.58$ & $3.38-5.69$ & $3.55-4.52$ & $3.58-4.57$ & & \\
\hline Mean \pm SD. & $4.43 \pm 0.88$ & $4.28 \pm 0.73$ & $4.14 \pm 0.32$ & $4.03 \pm 0.37$ & $4.655^{\circ}$ & $0.017^{*}$ \\
\hline Median & 4.39 & 4.10 & 4.17 & 4.02 & & \\
\hline Ppre. & & 0.148 & $0.001^{\circ}$ & $0.006^{\circ}$ & & \\
\hline Sig. bet. periods & \multicolumn{4}{|c|}{$\mathrm{p}_{1}=0.343, \mathrm{p}_{2}=0.414, \mathrm{p}_{3}=0.681$} & & \\
\hline Study cases $(n=10)$ & & & & & \multirow{4}{*}{$11.431^{\circ}$} & \multirow{4}{*}{$<0.001^{\circ}$} \\
\hline Min. - Max. & $3.37-5.06$ & $2.70-5.50$ & $3.06-3.98$ & $2.82-3.82$ & & \\
\hline Mean \pm SD & $4.35 \pm 0.61$ & $3.89 \pm 0.62$ & $3.45 \pm 0.27$ & $3.29 \pm 0.34$ & & \\
\hline Median & 4.30 & 3.80 & 3.40 & 3.36 & & \\
\hline $\mathbf{p}_{\text {pre. }}$ & & 0.062 & $0.001^{\circ}$ & $<0.001^{\circ}$ & & \\
\hline Sig. bet. periods & \multicolumn{4}{|c|}{$\mathrm{p}_{1}=0.123, \mathrm{p}_{2}=0.060, \mathrm{p}_{3}=0.275$} & & \\
\hline T & 0.244 & 1.388 & $4.668^{\circ}$ & $3.976^{\circ}$ & & \\
\hline $\mathbf{P}$ & 0.810 & 0.179 & $<0.001^{\circ}$ & $0.002^{\circ}$ & & \\
\hline
\end{tabular}

F: F test for ANOVA with repeated measures, sig. bet. periods was done using Post Hoc Test (LSD)

t: Student t-test

$\mathrm{p}_{\mathrm{pre}} \mathrm{p}$ value for comparison between pre with each other periods

$\mathrm{p}_{1}$ : $\mathrm{p}$ value for comparison between $1^{\text {st }}$ with $2^{\text {nd }}$ month post-operative

$\mathrm{p}_{2}$ : $\mathrm{p}$ value for comparison between $1^{\text {st }}$ with $3^{\text {rd }}$ month post-operative

$p_{3}$ : $p$ value for comparison between $2^{\text {nd }}$ with $3^{\text {rd }}$ month post- operative

*: Statistically significant at $\mathrm{p} \leq 0.05$

The bone level was higher in the study group than in the control group. The relation between the two groups was not statistically significant on the first month $(p=0.179)$ but on the second and the third months, it was statistically significant ( $\mathrm{p}=0.001$ and 0.002 respectively).

\section{DISCUSSION}

The present study was carried out to evaluate the effect of PRF on healing after surgical removal of mesio-angular position B impacted mandibular third molars.

In our study the cases were divided into two groups: a control group and a study group. Each group was composed of ten patients.

Following the surgical extraction of the impacted mandibular third molars, the extraction sockets in the control group were left to heal spontaneously. While in the study group, PRF was placed into the surgical site.

The post-operative evaluation was done clinically and radiographically. Regarding the post-operative pain, the present study showed less pain in the study group than in the control group on the second, fourth and seventh postoperative days but the difference was not significant. As regards the post-operative swelling, there was significantly less swelling in the study group than in the control group on the second and fourth post-operative days. Post-operative trismus was also less pronounced in the study group than in the control group although the difference was not significant.

This finding is in agreement with Girish Rao et al. 2013 (28), who conducted a study to evaluate bone regeneration in extraction sockets with autologous PRF. They observed accelerated soft tissue healing at all test sites treated with PRF compared with the control sites. The soft tissue parameters assessed qualitatively were: post-operative swelling, trismus, erythema, pus formation and wound dehiscence in the first week of extraction.

Also, Krumer N et al. 2015 (29), who conducted a study to evaluate the treatment outcome after impacted third molar surgery with the use of PRF, concluded that the application of PRF lessened the severity of immediate post-operative sequelae.

On the seventh post-operative day, sutures were removed, good gingival healing was found, no signs of infection or inflammation and no wound dehiscence were found in any patient.

This confirms findings reported by Singh et al. 2012 (30), who showed that autologous PRF is biocompatible and significantly improved soft tissue healing when placed in extraction sites.

Also, this is in accordance with the findings of Gassling et al. 2010 (31), who proved in their study that PRF with its intrinsic cytokines helps in wound healing by moderating the inflammation

Regarding the bone density, starting from the first to the third month post-operatively, there was slightly denser bone in the study group than in the control group. The difference among the study and the control groups was not statistically significant on the first post-operative month $(\mathrm{p}=0.908)$, but it was statistically significant on the second and third postoperative month ( $\mathrm{p}=0.028,0.013$ respectively).

The alveolar bone height was assessed radiographically from the cemento-enamel junction (CEJ) to the alveolar bone crest $(\mathrm{ABC})$ on the distal aspect of the mandibular second molars using the J Image program. Pre-operatively, the bone level was slightly lower in the control group than the study group, but the difference was not statistically significant $(p=.810)$. Starting from the first to the third month post-operatively, the bone level was higher in the study group than in the control group. The relation between the two groups was not statistically significant on the first month $(\mathrm{p}=0.179)$, but on the second and the third month, it was statistically significant $(\mathrm{p}=0.001$ and 0.002 respectively).

This is in agreement with the findings of Singh et al. 2012 (30), who found in their study that PRF has significantly improved soft tissue healing, bone regeneration and increase in bone density in extraction sockets.

Also, Girish et al. 2013 (28) found in their study a definite improvement in the regeneration of bone after third molar surgery in cases treated with PRF as compared to the control group post-operatively. They also stated that this increase in the bone density signifies and highlights the use of PRF, certainly as a valid method in accelerating hard tissue regeneration. 
Moreover, Choukroun et al. 2006 (32) evaluated the potential of PRF in combination with freeze dried bone allograft (FDBA) to enhance bone regeneration in human sinus floor elevation. Nine sinus floor augmentations were performed. In 6 sites, PRF was added to FDBA particles (test group), and in 3 sites FDBA without PRF was used (control group). Four months later for the test group and 8 months later for the control group, bone specimens were harvested from the augmented region during the implant insertion procedure. The histological results revealed that bone maturation in PRF group at 4 months of healing was similar to that in the control group at 8 months. Thus they concluded that sinus floor augmentation with FDBA and PRF leads to a reduction of healing time prior to implant placement.

On the other hand, Ozgur Baslarli et al. 2015 (33) investigated the healing potential of bone by comparing PRF-treated and non-PRF-treated extraction sockets. In conclusion PRF-treated extraction sockets did not demonstrate any difference in bone regeneration than non PRF-treated extraction sockets post-operatively after 4 and 12 weeks.

Also, Zhang et al. 2012 (34) conducted histological and clinical evaluations of 10 patients who underwent sinus lifting. As a test group, six sinus floor elevations were grafted with a bovine bone graft (Bio-Oss) and PRF mixture, and as a control group, five sinuses were treated with Bio-Oss alone. Their results revealed that there was no difference in the new bone between the group receiving only (Bio-Oss) and that receiving PRF in combination with bovine bone graft 6 months after sinus-lifting surgery.

\section{CONCLUSIONS}

From the results of this study we can conclude that:

- It is clear that PRF is biocompatible and can improve both soft tissue healing and bone regeneration.

- PRF is an effective treatment option to treat osseous defects at the distal surface of the second molar.

\section{CONFLICT OF INTEREST:}

The authors declare that they have no conflicts of interest.

\section{REFERENCES}

1. Kim J. Cone beam computed tomography findings of ectopic mandibular third molar in the mandibular condyle. Imaging Sci Dent. 2011; 41: 135-7.

2. Avendaño C, García P, Castellón V, Aytés B, Escoda G. Morbidity of third molar extraction in patients between 12 and 18 years of age. Medicina Oral Patologia Oral Cir Bucal. 2005; 10: 422-31.

3. Jerjes W, El-Maaytah M, Swinson B, Banu B, Upile T, Al-Khawalde M. Experience versus complication rate in third molar surgery. Head Face Med. 2006; 2: 14.

4. Susarla S, Blaeser B, Magalnick D. Third molar surgery and associated complications. Oral MaxillofacSurg Clin North Am. 2003; 15: 177-86.
5. Dadson TB. Reconstruction of alveolar bone defects after extraction of mandibular third molars. Oral Surg Oral Med Oral Pathol. 1996; 82: 241-7.

6. Gassling VL, Açil Y, Springer IN, Hubert N, Wiltfang J. Platelet-rich plasma and platelet-rich fibrin in human cell culture. Oral Surg Oral Med Oral Pathol Oral Radiol Endod. 2009; 108: 48-55.

7. Tozum T, Demiralp B. Platelet-rich plasma: a promising innovation in dentistry. J Can Dent Assoc. 2003; 69: 664-9.

8. El Gamdi H, Mokeem S, Anil S. Current concepts in alveolar ridge augmentation: a critical appraisal. SDJ. 2007; 19: 74-90.

9. Nevins M, Giannobile WV, McGuire MK, Kao RT, Mellonig JT, Hinrichs JE, et al. Platelet-derived growth factor stimulates bone fill and rate of attachment level gain: Results of a large multicenter randomized controlled trial. J Periodontal. 2005; 76: 2205-15.

10. Soffer E, Ouhayoun JP, Anagnostou F. Fibrin sealants and platelet preparations in bone and periodontal healing. Oral Surg Oral Med Oral Pathol Oral Radiol Endod. 2003; 95: 521-8.

11. Marx RE, Carlson ER, Eichstaedt RM, Schimmele SR, Strauss JE, Georgeff KR. Platelet-rich plasma: Growth factor enhancement for bone grafts. Oral Surg Oral Med Oral Pathol Oral Radiol Endod. 1998; 85: 638-46.

12. Lee H, Choi B, Jung J, Zhu S, Lee S, Huh J, et al. Maxillary sinus floor augmentation using autogenous bone grafts and platelet enriched fibrin glue with simultaneous implant placement. Oral Surg Oral Med Oral Pathol Oral Radiol Endod. 2007; 103: 329-33.

13. Del Corso M, Micheal T, David M, Dohan D. Use of an autologous leucocyte and platelet rich fibrin (LPRF) membrane in post avulsion sites: an overview of Choukroun's PRF. JIACD. 2010; 1: 27-35.

14. Sunitha R, Munirathnam N. Platelet rich fibrin: evolution of a second generation platelet concentrate. Indian J Dent Res. 2008; 19: 42-6.

15. Dohan DM, Choukroun J, Diss A, Dohan SL, Dohan J. Platelet rich fibrin (PRF): a second- generation platelet concentrate. Part I: technological concepts and evolution. Oral Surg Oral Med Oral Pathol Oral Radiol Endod. 2006; 101: 37-44.

16. Weibrich G, Kleis W, Buch R, Hitzler W, Hafner G. The Harvest Smart PRP system versus the Friadent-Schutze platelet-rich plasma kit. Clin Oral Implants Res. 2003; 14: 233-9.

17. Toffler M, Toscano N, Holtzclaw D, Corso MD, Dohan Ehrenfest DM. Introducing Choukroun's platelet rich fibrin (PRF) to the reconstructive surgery. J Implant Adv Clin Dent. 2009; 1: 21-30.

18. Dohan DM, Choukroun J, Diss A, Dohan SL, Dohan AJ, Mouhyi J, et al. Platelet rich fibrin (PRF): a second generation platelet concentrate. Part II: platelet related biologic features. Oral Surg Oral Med Oral Pathol Oral Radiol Endod. 2006; 101: e45-e50. 
19. Throat M, Pradeep A, Pallavi B. Clinical effects of autologous platelet rich fibrin in the treatment of intrabony defects: a controlled clinical trial. J Clin Periodontal. 2011; 38: 925-32.

20. Simonpieri A, Del Corso M, Sammartino G, Dohan D. The relevance of Choukroun's platelet rich fibrin and metronidazole during complex maxillary rehabilitations using bone allograft. Part I: a new grafting protocol. Implant Dent. 2009; 18: 102-11.

21. Vence B, Mandelaris G, Forbes D. Management of dento-alveolar ridge defects for implant site development: an interdisciplinary approach. Compend Cont Ed Dent. 2009; 30: 250-62.

22. Dohan D, Choukroun J, Diss A, Dohan S, Dohan A, Mouhyi J, et al. Platalet rich fibrin (PRF): a second generation platelet concentrate. Part III: leucocyte activation: a new feature for platelet concentrates. Oral Surg Oral Med Oral Pathol Oral Radiol Endod. 2006; 101: 51-5.

23. David M, Dohan D, Del Corso M, Antoine D, Jaafar M. Three dimensional architecture and cell composition of a Choukroun's platelet rich fibrin clot and membrane. J Periodontal. 2010; 81: 546-55.

24. Hiremath H, Saikalyan S, Kulkarni S, Hiremath V. Second generation platelet concentrate (PRF) as a pulpotomy medicament in a permanent molar with pulpitis: a case report. Int Endod. J 2012; 45: 105-12.

25. Pasqualini D, Cocero N, Castella A, Mela L, Bracco P. Primary and secondary closure of the surgical wound after removal of impacted mandibular third molars: a comparative study. Int J Oral Maxillofac Surg. 2005; 34: 52-7.

26. Bamgbose B, Akinwande J, Adeyemo W, Ladeinde A, Arotiba G, Ogunlewe M. Effects of co-administered dexamethasone and diclofenac potassium on pain, swelling and trismus following third molar surgery. Head Face Med. 2005; 1: 11.

27. Kirkpatrick LA, Feeney BC. A simple guide to IBM SPSS statistics for version 20.0. Student ed. Belmont, Calif.: Wadsworth, Cengage Learning; 2013.

28. Girish Rao S, Bhat P, Nagesh KS, Rao GH, Mirle B, Kharbhari L, et al. Bone Regeneration in Extraction Sockets with Autologous Platelet Rich Fibrin Gel. J Maxillofac Oral Surg. 2013; 12: 11-6.

29. Krumar N, Prasad K, Ramanujam L, K R, Dexith J, Chauhan A. Evaluation of treatment outcome after impacted mandibular third molar surgery with the use of autologous platelet rich fibrin: a randomized controlled clinical study. J Oral Maxillofac Surg. 2015; 73; 1042-9.

30. Singh A, Kohil M, Gupta N. Platelet rich fibrin: a noval approach for osseous regeneration. J Maxillofac Oral Surg. 2012; 11: 430-4.

31. Gassling V, Douglas T, Warnke P, Wiltfang Y, Becker S. Platelet rich fibrin membranes as scaffolds for periosteal tissue engineering. Clin Oral Implants Res. 2010; 21: 543-9.
32. Choukroun J, Diss A, Simonpieri A, Girard M, Schoeffler C, Dohan S, et al. Platelet rich fibrin (PRF): a second generation platelet concentrate. Part V: histologic evaluation of PRF effects on bone allograft maturation in sinus lift. Oral Surg Oral Med Oral Pathol Oral Radiol Endod. 2006; 101: 299-303.

33. Baslarli O, Tumer C, Ugur O, Vatankulu B. Evaluation of osteoplastic activity in extraction sockets treated with platelet-rich fibrin. Med Oral Pathol Oral Cir Buccal. 2015; 20: e11-e116.

34. Zhang Y, Tangl S, Huber C, Lin Y, Qiu L, Rausch-Fan X. Effects of Choukroun's platelet rich fibrin on bone regeneration in combination with deproteinized bovine bone mineral in maxillary sinus augmentation: a histological and histomorphometric study. J Craniomaxillofac Surg. 2012; 40: 321-8. 